\title{
Immunological Follow-up of Hydatid Cyst Cases
}

\section{Vedat Bulut ${ }^{+}$, Fulya Ilhan*, Ahmet Yasar Yucel**, Suleyman Onal**, Yavuz Ilhan***, Ahmet Godekmerdan****}

\author{
Immunology Department *Health Sciences College **Microbiology and Clinical \\ Microbiology Department ***General Surgery Department *****Parasitology Department, Medical Faculty, \\ Firat University, Elazig, Turkey
}

Hydatid disease is caused by Echinococcus granulosus. In this study, we aimed to investigate the benefit of monitoring cases with hydatid cyst by means of immune components in patients in a long-term follow-up after surgery. Eighty-four preoperative and postoperative serum samples from 14 cases undergoing surgery for hydatid disease were evaluated in terms of immune parameters, such as total and specific IgE, IgG, IgM, IgA and complement. Total and specific IgE were determined by ELISA. Specific $I g G$ levels were measured by indirect hemaglutination.Total IgG, IgM, IgA and complement (C3 and C4) were detected by nephelometry. Imaging studies were also carried out during the follow-up. In none of the patients hydatid cysts were detected during the follow-up. Total IgE levels in the sera of the patients decreased to normal six months after surgery. Although specific IgE against echinococcal antigens decreased one year after operation, levels were still significantly high. There were no changes in the levels of anti-Echinococcus IgG and total IgG in follow-up period. Additionally, other parameters, such as IgA, IgM, C3 and C4, were not affected.

Key words: hydatid cyst - immune system

Hydatid disease is caused by Echinococcus granulosus in the liver, the spleen and the lungs. Many cases are asymptomatic, and physical examination is not useful, unless the cyst enlarges and pressures on surrounding tissues and vascular structures. Due to antigens in cystic fluid, antibody production can be induced in the host. Cassoni reaction is a skin test that is not in use because of $20 \%$ false negative and $30 \%$ false positive results (Imren 1997). Weinberg test is complicated to be performed and was replaced with serological tests. Quantitative determination of specific IgE antibodies to E. granulosus and total $\mathrm{IgE}$ levels in sera, using ELISA, might be a useful tool not only in diagnosis, but also in follow-up period after surgical applications in order to monitor remaining or relapsing hydatid cysts (Dessaint et al. 1975). The outcome of a study in surgically confirmed cases, showed that ELISA is a good screening test with $88.2 \%$ sensitivity, $88.8 \%$ specificity and $88.5 \%$ diagnostic efficacy (Kaddah et al. 1992). Additionally, complement cascade activation and immune complex deposition due to antibodies in patients

\footnotetext{
${ }^{+}$Corresponding author. Fax: +90-424-237-9138. E-mail: vbulut@superonline.com.tr

Received 24 April 2000

Accepted 10 April 2001
}

with hydatid cyst have been reported (Ali Khan \& Rausch 1987, DAmelio et al. 1989). In this study, we aimed to investigate the presence of immunoglobulins and complement, in a long-term followup after surgery.

\section{MATERIALS AND METHODS}

Fourteen cases (mean of ages: $34 \pm 7$ ) with hydatid cyst disease were enrolled in the study. Diagnosis of the patients was established by ultrasound, CT and serological tests and confirmed by parasitological examination of cystic fluid after surgery. All cases underwent surgery for hydatid disease. Partial cystectomy plus drainage were performed on ten patients and complete cystotomy plus drainage on remaining four patients. Prior to and after surgical approach (1 day, 1 week, 1 month, 6 months and 1 year), $15 \mathrm{ml}$ of venous blood from each case were obtained. Serum was separated by centrifugation. Eighty-four preoperative and postoperative serum samples were evaluated for specific $\operatorname{IgE}$ and $\operatorname{IgG}$, and total $\operatorname{IgE}$, IgG, IgM, $\operatorname{IgA}$ and complement factors. Total and specific IgE were determined by ELISA (Bioclone, Marrickville, Australia and Dr Fook, Neuss, Germany, respectively). Specific IgG levels were measured by indirect hemaglutination (InternationalImmuno Diagnostics, CA, USA). Total IgG, IgM, $\mathrm{IgA}$ and complements (C3 and $\mathrm{C} 4)$ were detected by using nephelometry (Beckman Array 360, CA, USA). Imaging studies were also carried out dur- 
ing the follow-up. As a control group, 32 healthy voluntaries were enrolled to the study (mean age: $34 \pm 7)$. Statistical analysis was performed by Kruskal-Wallis (nonparametric one-way ANOVA), Student's $t$ test between groups showing normal Gauss distribution, Mann-Whitney U test between groups not showing normal Gauss distribution, correlation analysis (Spearman) in SPSS 7.0.5 for Windows 95. p values below 0.05 were accepted as statistically significant.

\section{RESULTS}

In none of the patients cysts were detected during the follow-up. Total IgE levels decreased gradually to normal six months after surgery (Fig. 1). Although specific IgE against echinococcal antigens also decreased, its levels were still significantly high (Fig. 2). There was no alteration in the levels of anti-Echinococcus $\mathrm{IgG}$ and total $\mathrm{IgG}$ in follow-up period (Tables I, II). Additionally, other parameters, such as $\mathrm{IgA}, \operatorname{IgM}, \mathrm{C} 3$ and $\mathrm{C} 4$, were not affected (Tables I, II). IgA and IgG levels in the patients with hydatid cyst were found to be slightly higher than in healthy individuals (Table I) but with no statistical significance. There was no difference among time point measurements of C3 and C4 levels (Table III).

\section{DISCUSSION}

In the study, a highly significant correlation was obtained between levels of total serum $\operatorname{IgE}$ and specific $\operatorname{IgE}$ antibodies $\left(\mathrm{r}_{\mathrm{s}}=0.289, \mathrm{p}<0.001\right)$. This finding is in agreement with the report of Dessaint et al. (1975). While total IgE levels declined to normal values six months after surgery, specific $\operatorname{IgE}$ levels maintained their high levels longer than six months. This is most likely due to polyclonal activation of B lymphocytes by E. granulosus antigens, such as antigen 5, Em 16, Em 18 and antigen B, also present in E. alveolaris (Ayadi et al. 1995, Abdel et al. 1996, Nirmalan \& Craig 1997). There is no information that evaluates half-lives

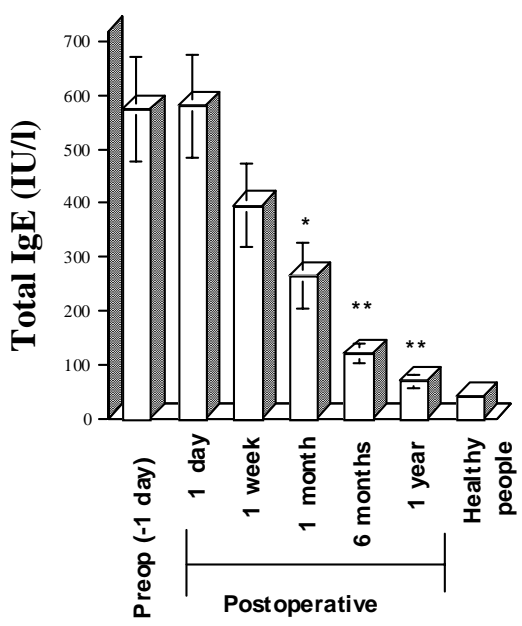

Fig. 1: total IgE levels (IU/1) of 14 cases were shown. Results are expressed as mean \pm SEM bars. Standard of the laboratory, in which the study was carried out, was obtained from a group of healthy individuals in quality control procedures $(\mathrm{n}: 30)$ $*: \mathrm{p}<0.01 ; * *: \mathrm{p}<0.001$

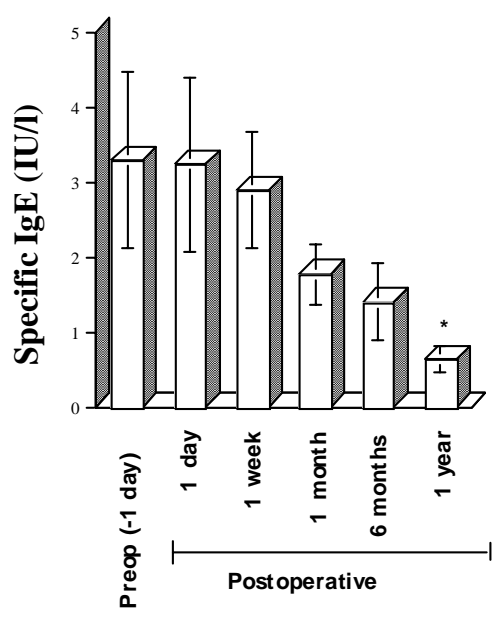

Fig. 2: specific IgE levels (IU/ml) of 14 cases are shown. Results are expressed as mean \pm SEM bars; $*$ : $p<0.01$

TABLE I

Frequency of specific IgG levels in sera of the cases $(n=14)$

\begin{tabular}{lcccccc}
\hline \multicolumn{7}{c}{ Time } \\
\hline Dilution & -1 day & +1 day & +1 week & +1 months & +6 months & +1 year \\
\hline $1 / 40$ & 0 & 0 & 0 & 0 & 2 & 4 \\
$1 / 80$ & 3 & 2 & 4 & 4 & 3 & 3 \\
$1 / 160$ & 2 & 2 & 1 & 1 & 2 & 1 \\
$1 / 320$ & 0 & 1 & 1 & 1 & 2 & 0 \\
$1 / 640$ & 3 & 1 & 1 & 7 & 5 & 5 \\
$1 / 1280$ & 6 & 8 & 7 & 1 & 5 \\
\hline
\end{tabular}

Figures are number of cases. 
TABLE II

Immunoglobulin levels $(\mathrm{mg} / \mathrm{dl})$ in sera of 14 cases

\begin{tabular}{lccc}
\hline Time & IgG & IgM & IgA \\
\hline-1 day & $1369.14 \pm 113.48$ & $185.86 \pm 22.84$ & $295.64 \pm 40.81$ \\
+1 day & $1199.71 \pm 71.52$ & $168.86 \pm 14.29$ & $246.36 \pm 12.38$ \\
+1 week & $1247.43 \pm 82.54$ & $178.83 \pm 19.89$ & $286.64 \pm 39.20$ \\
+1 month & $1338.64 \pm 103.47$ & $204.43 \pm 15.90$ & $296.86 \pm 37.48$ \\
+6 months & $1209.93 \pm 89.02$ & $187.85 \pm 15.21$ & $291.36 \pm 20.01$ \\
+1 year & $1251.93 \pm 88.33$ & $193.56 \pm 14.01$ & $186.58 \pm 35.05$ \\
Lab st. & $984.91 \pm 37.59$ & $181.40 \pm 11.57$ & \\
\hline
\end{tabular}

Results are expressed as mean \pm SEM. Laboratory standard values were obtained from 500 healthy individuals.

TABLE III

C3 and C4 levels (mg/dl) in sera of 14 cases

\begin{tabular}{lcc}
\hline Time & $\mathrm{C} 3$ & $\mathrm{C} 4$ \\
\hline -1 day & $170.14 \pm 12.08$ & $36.64 \pm 2.86$ \\
+ 1 day & $157.00 \pm 9.84$ & $35.02 \pm 2.90$ \\
+ 1 week & $179.93 \pm 19.05$ & $39.29 \pm 4.09$ \\
+ 1 month & $168.28 \pm 14.44$ & $39.29 \pm 2.53$ \\
+6 months & $164.50 \pm 11.61$ & $35.25 \pm 3.15$ \\
+ 1 year & $157.64 \pm 11.57$ & $36.06 \pm 3.23$ \\
Lab st. & $152.37 \pm 5.26$ & $32.11 \pm 1.84$ \\
\hline
\end{tabular}

Results are expressed as mean \pm SEMs. Laboratory standard values were obtained from 500 healthy individuals.

of specific IgE against these antigens. We examined the patients in order to exclude echinococcosis in other tissues, including the lungs, performing chest $\mathrm{X}$-rays. The commercial antigen used for detecting specific IgE in the system is obtained from cyst fluid by crude extraction and purification by chromatography. Probably, specific IgE against $E$. granulosus has a long half-life or there is antigenic exposure after surgery in spite of no relapse of the disease.

We could not find any alteration in complement levels (C3 and $\mathrm{C} 4)$ in a quantitative manner. Assesing total complement activity by using Complement Hemolytic Activity $\left(\mathrm{CH}_{50}\right)$ assays might give more useful information. During the follow-up period, $\operatorname{Ig} \mathrm{A}$ and $\operatorname{IgM}$ levels did not change, as well, and no patients in the study presented clinical manifestations indicating immunecomplex patterns. When compared with the levels of healthy individuals, $\operatorname{IgA}$ and $\operatorname{IgG}$ levels in the cases were slightly higher prior to and after surgical operation. However, there was no statistical significance $(\mathrm{p}>0.05)$.

\section{REFERENCES}

Abdel Aal TM, al-Hady HM, Youssef FG, Fahmi IA, Abou-el-Saoud SM, Ramadan NI 1996. Studies on the most reactive purified antigen for immunodiagnosis of hydatid disease. J Egypt Soc Parasitol 26: 297-303.

Ali Khan Z, Rausch RL 1987. Demonstration of amyloid and immune complex deposits in renal and hepatic parenchyma of Alaskan alveolar hydatid disease patients. Ann Trop Med Parasitol 81:381-392.

Ayadi A, Dutoit E, Sendid B, Camus D 1995. Specific diagnostic antigens of Echinococcus granulosus detected by western blot. Parasite 2: 119-123.

D'Amelio R, De Rosa F, Pontesilli O, Dayal R, Brighouse G, Teggi A, Barnet M, Lambert PH 1989. Hydatid disease: analysis of parasite antigens in circulating immune complexes and in preformed hydatid antigen-antibody complexes. Med Microbiol Immunol 178: 177-186.

Dessaint JP, Bout D, Wattre P, Capron A 1975. Quantitative determination of specific IgE antibodies to Echinococcus granulosus and IgE levels in sera from patients with hydatid disease. Immunology 29: 813823.

Imren AH 1997. Laboratory in Clinical Diagnosis, Mentes Publication, Istanbul, p. 571-572.

Kaddah MH, Maher KM, Hassanein HI, Farrag AI, Shaker ZA, Khalafallah AM 1992. Evaluation of different immunodiagnostic techniques for diagnosis of hydatidosis in Egypt. $J$ Egypt Soc Parasitol 22: 653-665.

Nirmalan N, Craig PS 1997. Immunoblot evaluation of the species-specificity of EM 18 and EM 16 antigens for serodiagnosis of human alveolar echinococcosis. Trans R Soc Trop Med Hyg 91: 484-486. 